\title{
Sensitivity and specificity of a prenatal screening method using the combination of maternal age and fetal nuchal translucency thickness for fetal aneuploidy: a clinical study in eastern India
}

\section{Kalyansree Chaudhury ${ }^{1}$, Kanchan Mukherjee ${ }^{2 *}$}

\author{
${ }^{1}$ Department of Obstetrics \& Gynaecology, Burdwan Medical College, Burdwan, West Bengal, India \\ ${ }^{2}$ Remedy Medical Services, Kolkata, India
}

Received: 04 November 2015

Accepted: 12 December 2015

\section{*Correspondence:}

Dr. Kanchan Mukherjee,

E-mail: mukherjee.kanchan@gmail.com

Copyright: (c) the author(s), publisher and licensee Medip Academy. This is an open-access article distributed under the terms of the Creative Commons Attribution Non-Commercial License, which permits unrestricted non-commercial use, distribution, and reproduction in any medium, provided the original work is properly cited.

\section{ABSTRACT}

Background: Down's syndrome (DS), one of the commonest fetal aneuploidy, is associated with mental retardation and physical disabilities in the affected individual. The aim of this study is to determine the sensitivity and specificity of a screening method using the combination of maternal age and fetal nuchal translucency thickness for all fetal aneuploidy including DS in our population.

Methods: All 412 mothers, in this retrospective study, had an ultrasound scan between 11 weeks and 13 weeks 6 days of gestation when nuchal translucency thickness of the fetus was measured. The individual risk of each mother was calculated using a software that takes maternal age, nuchal translucency thickness and crown-rump length into consideration. Using a cut-off risk estimate of 1 in 300, the women were grouped into screen positive and screen negative. The chromosomal status of all the fetuses were checked either by amniocentesis and chromosomal study or by birth of a phenotypically normal child. Sensitivity and Specificity of the screening method were calculated from the available data.

Results: Sensitivity of the screening test for fetal trisomy 21 was $75 \%$ and for all fetal aneuploidy was $80 \%$. Specificity of the screening test for all fetal aneuploidy was $91.4 \%$ and False Positive Rate was $8.6 \%$. Our results are consistent with the results obtained in other large international studies.

Conclusions: Combination of maternal age and fetal nuchal translucency thickness is an effective prenatal screening method for fetal aneuploidy.

Keywords: Down syndrome, Fetal aneuploidy, Maternal age, Fetal nuchal translucency thickness, Sensitivity, Specificity

\section{INTRODUCTION}

Down Syndrome (DS), the single most common genetic cause for mental retardation ${ }^{1}$, results when either the whole or part of the chromosome 21 is present in three copies instead of two. The effects of DS involve a range of medical conditions in addition to cognitive impairment and intellectual disability in children and adults. ${ }^{2}$

Apart from variable degrees of mental retardation ${ }^{3}$, affected babies have associated physical disabilities, particularly heart, gastrointestinal tract, eyes and ears. ${ }^{4}$ Beside the devastating effect on the family, it makes significant demands on the society, particularly health care system. One study from the US reported that the health care costs of DS children was upto 13 times higher than for children without DS. ${ }^{5}$ That is not all. To make matters worse, DS is the most common chromosomal condition diagnosed in the newborn in the United States. ${ }^{6}$

The only remedy available for DS is prenatal diagnosis and termination of affected pregnancy. The current 
methods of prenatal diagnosis e.g. chorionic villus sampling and amniocentesis are invasive which carry risk of miscarriage and have financial cost implications. This means that the entire pregnant population cannot be subjected to these diagnostic methods. ${ }^{7}$ Screening is a scientific strategy to identify the asymptomatic high risk population who are more likely to have the problem. Invasive test on this identified population will detect maximum number of abnormalities with minimum complications. The first method of screening for DS, introduced in the early 1970s, was the association of DS with advanced maternal age. Nuchal translucency (NT) is the sonographic appearance of subcutaneous accumulation of fluid behind the fetal neck in the first trimester of pregnancy. ${ }^{7}$ In 1990s increased nuchal translucency was noted to be an ultrasound marker for DS and the screening by combination of maternal age and nuchal translucency thickness was introduced. ${ }^{7-9}$

Quite a number of studies have attested the effectiveness of NT as screening test for DS in western nations. ${ }^{10,11}$ The aim of this study is to determine the sensitivity and specificity of a screening method, in which the combination of NT and maternal age is used, for DS in fetus and for all fetal aneuploidy in our population.

\section{METHODS}

In this retrospective study we reviewed the outcome of 412 mothers who had nuchal translucency scan for prenatal screening at a private diagnostic clinic in Kolkata between May 2010 and January 2014. Local ethics committee approval was obtained and all patients gave informed consent.

Over this period, of the 491 mothers, who had nuchal translucency scan with singleton live pregnancy between 11 weeks and 13 weeks 6 days gestation, the fetal chromosomal status of 21 mothers (13 mothers who had stillbirths and 8 mothers who had second-trimester miscarriage) was not available and 58 mothers were lost in follow up. Hence, these women were excluded from the study. The remaining 412 mothers who were followed up till after delivery with known fetal chromosomal status, were included in this study.

All mothers, after counselling thoroughly regarding the procedure and purpose of the nuchal translucency scan, gave informed consent.

NT scan was done as per Fetal Medicine Foundation, UK (FMF) protocol. The procedures were performed between 11 weeks and 13 weeks 6 days gestation when fetal crown-rump length was between 45 and $84 \mathrm{~mm}$.

Voluson E8 (expert) ultrasound machine was used for these procedures. There were times when optimum images could not be obtained via transabdominal route and patients were asked to wait until satisfactory images were available. The transvaginal method was not used, as it is rarely successful in getting a good image for NT when transabdominal examination fails due to suboptimal fetal position.

As recommended by the FMF, only fetal head and upper one third of thorax were included in the image with largest possible magnification. A good sagittal section of the fetus in the neutral position was obtained first. It is expected that while the hyperextended fetal head would increase NT measurement by $0.6 \mathrm{~mm}$, a flexed head would decrease it by $0.4 \mathrm{~mm}$. Care was taken to distinguish between fetal skin and amnion because, at this gestation, both structures appear as thin membranes. This is achieved by waiting for the spontaneous movement to take the fetus away from amniotic membrane. Alternatively, the fetus is bounced off the amniotic membrane by asking the mother to cough or tapping the abdomen.

The maximum thickness of the subcutaneous translucency between fetal skin and the soft tissue overlying the cervical spine was measured. The calipers were placed on the lines that define the NT thickness. The crossbar of the caliper was placed in a way that it was hardly visible as it merged with the white line of the borders and not in the nuchal fluid.

The individual risk of each mother was calculated following ultrasound scan, by using FMF software that takes the maternal age, crown-rump length (CRL) and nuchal translucency thickness into account. Using a cutoff value of 1 in 300, all the women were grouped into either screen-negative (if the risk $<1$ in 300) or screenpositive (if the risk is $\geq 1$ in 300 ). The fetal chromosomal status of the screen-positive mothers was checked by amniocentesis and karyotyping and that of the screennegative mothers was confirmed by birth of a phenotypically normal baby. All children, who were considered phenotypically normal at birth by the paediatrician, were considered to be euploid. Continuous variables of the two group were compared using ' $t$ ' test. $\mathrm{p}<0.05$ was considered statistically significant.

Maternal details and the ultrasound findings were recorded at the time of ultrasound scan in the clinic. Pregnancy outcome data were logged subsequently at the database as it was available from the mothers in the follow-up or by direct questionnaire.

All procedures were done by one of the authors (KM) trained in fetal medicine.

The definitions of the relevant terms and their calculations are given below:

$\mathrm{TP}=$ True Positve $=\mathrm{A}$ person who tests positive and has the abnormality i.e. the disease.

$\mathrm{FP}=$ False Positive $=$ A person who tests positive and does not have the abnormality. 
$\mathrm{TN}=$ True Negative $=\mathrm{A}$ person who tests negative and does not have the abnormality

$\mathrm{FN}=$ False Negative $=\mathrm{A}$ person who tests negative and has the abnormality

Sensitivity refers to the ability of a test to detect the proportion of individuals with abnormalities correctly out of all individuals with abnormalities. It is expressed in percentage. Sensitivity is also referred as 'Detection Rate' or 'True Positive Rate' in percentage. The complement of sensitivity is the False Negative Rate. ${ }^{12}$

Sensitivity is calculated as below ${ }^{13}$

Sensitivity $=\frac{\mathrm{TP}}{\mathrm{TN}+\mathrm{FP}} \times 100 \%$

False Negative Rate can be calculated directly as below:

False Negative rate $=\frac{\mathrm{FN}}{\mathrm{TN}+\mathrm{FP}} \times 100 \%$

Alternatively, false negative rate can be indirectly calculated as below:

False Negative rate $=100 \%$ - sensitivity

Specificity refers to the ability of a test to detect the proportion of individuals without abnormalities correctly out of all individuals without abnormalities. It is expressed in percentage. Specificity is also referred as 'True Negative Rate' in percentage. The complement of specificity is the False Positive Rate. ${ }^{12}$

Specificity is calculated as below ${ }^{13}$

Specificity $=\frac{\mathrm{TN}}{\mathrm{TN}+\mathrm{FP}} \times 100 \%$

False Positive Rate can be directly calculated as below:

False Positive Rate $=\frac{\mathrm{FP}}{\mathrm{TP}+\mathrm{FN}} \times 100 \%$

False Positive Rate can also be indirectly calculated as below:

False Positive rate $=100 \%-$ specificity

\section{RESULTS}

In this retrospective study over a period of three years and nine months, 412 mothers, who had prenatal nuchal translucency scan of the fetus and whose fetal chromosomal status were checked either by amniocentesis and karyotyping or by birth of a phenotypically normal baby, were reviewed. The mean age of the mothers was 32.15 years. $21.6 \%$ of the mothers were 35 years or more. There was no significant difference in the age or crown-rump length (CRL) between the screen-positive and screen-negative group. The only notable difference between the two groups was in NT thickness.

Pregnancy characteristics of the participating women are given in Table 1.

Table 1: Characteristics of the participating women.

\begin{tabular}{|c|c|c|c|c|}
\hline & $\begin{array}{l}\text { Screen } \\
\text { Negative } \\
(n=373)\end{array}$ & $\begin{array}{l}\text { Screen } \\
\text { Positive } \\
(n=39)\end{array}$ & $\begin{array}{l}\text { p } \\
\text { Value }\end{array}$ & $\begin{array}{l}\text { Rema- } \\
\text { rks }\end{array}$ \\
\hline $\begin{array}{l}\text { Age (in } \\
\text { years) } \\
\text { (Mean } \pm \\
\text { S.D) }\end{array}$ & $\begin{array}{l}31.8 \pm \\
5.04\end{array}$ & $\begin{array}{l}32.5 \pm \\
3.6\end{array}$ & $>0.05$ & $\begin{array}{l}\text { Not } \\
\text { signifi- } \\
\text { cant }\end{array}$ \\
\hline $\begin{array}{l}\text { CRL (in } \\
\text { mm) } \\
\text { (Mean } \pm \\
\text { S.D) }\end{array}$ & $\begin{array}{l}59.89 \pm \\
8.4\end{array}$ & $\begin{array}{l}58.45 \pm \\
8.65\end{array}$ & $>0.05$ & $\begin{array}{l}\text { Not } \\
\text { signifi- } \\
\text { cant }\end{array}$ \\
\hline $\begin{array}{l}\text { NT } \\
\text { thickness } \\
\text { (in mm) } \\
\text { (Mean } \pm \\
\text { S.D) }\end{array}$ & $\begin{array}{l}1.67 \pm \\
0.31\end{array}$ & $\begin{array}{l}2.57 \pm \\
0.69\end{array}$ & $<0.001$ & $\begin{array}{l}\text { Signifi- } \\
\text { cant }\end{array}$ \\
\hline
\end{tabular}

The whole study result showing the fetal chromosomal status in both screen-negative and screen-positive mothers is displayed in Table 2.

Table 2: Study result at a glance.

\begin{tabular}{|l|lll|}
\hline & \multicolumn{3}{|c|}{ Total number of fetuses $(\mathrm{n}=412)$} \\
\hline \multirow{2}{*}{$\begin{array}{l}\text { Total number } \\
\text { of mothers } \\
(\mathrm{n}=412)\end{array}$} & $\begin{array}{l}\text { Normal } \\
\text { fetus } \\
(\mathrm{n}=407)\end{array}$ & $\begin{array}{l}\text { Abnormal fetus } \\
(\mathrm{n}=5)\end{array}$ \\
& $\begin{array}{l}\text { Trisom } 21 \\
(\mathrm{n}=4)\end{array}$ & $\begin{array}{l}\text { Turner's } \\
\text { syndrome } \\
(\mathrm{n}=1)\end{array}$ \\
\hline $\begin{array}{l}\text { No. of screen- } \\
\text { negative mothers } \\
(\mathrm{n}=373)\end{array}$ & 372 & 1 & Nil \\
\hline $\begin{array}{l}\text { No. of screen- } \\
\text { positive mothers } \\
(\mathrm{n}=39)\end{array}$ & 35 & 3 & 1 \\
\hline
\end{tabular}

One mother, who was screen-negative, was detected having fetal abnormalities during anomaly scan at 18 weeks of gestation. Following amniocentesis, Fluorescence in situ Hybridization (FISH) probe revealed fetal trisomy 21 in this mother. It is relevant to mention that all the mothers, who had aneuploid fetus, underwent termination of pregnancy.

Calculation of sensitivity of screening test for Trisomy 21 in fetus is as below:

Sensitivity $=\frac{\mathrm{TP}}{\mathrm{TP}+\mathrm{FN}}=\frac{3}{3+1} \times 100 \%=75 \%$ 
Table 3: Screening test vis-à-vis fetal aneuploidy.

\begin{tabular}{|lll|}
\hline & $\begin{array}{l}\text { Trisomy } \\
(\mathrm{n}=4)\end{array}$ & $\begin{array}{l}\text { Turner's } \\
\text { syndrome } \\
(\mathrm{n}=1)\end{array}$ \\
\hline $\begin{array}{l}\text { No. of fetal aneuploidies } \\
\text { correctly detected by } \\
\text { screening test (TP) }\end{array}$ & 3 & 1 \\
\hline $\begin{array}{l}\text { No. of fetal aneuploidies } \\
\text { missed by screening test (FN) }\end{array}$ & 1 & 0 \\
\hline Total no. of fetal aneuploidies & 4 & 1 \\
\hline
\end{tabular}

False Negative Rate of screening test for Trisomy 21 in fetus is calculated as below:

False Negative rate $=100 \%$ - sensitivity $=100 \%-75 \%$ $=25 \%$

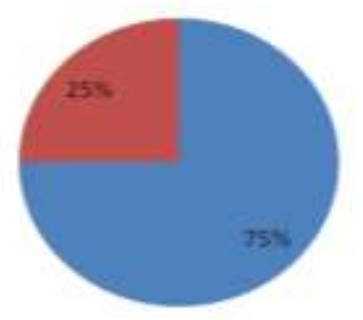

mSensitivity walse Negativerate

Figure 1: Pie chart showing sensitivity and false negative rate of screening test for Trisomy 21 in fetus.

Calculation of sensitivity of screening test for all fetal aneuploidy is as below:

Sensitivity $=\frac{\mathrm{TP}}{\mathrm{TP}+\mathrm{FN}} \times 100 \%=\frac{4}{4+1} \times 100 \%=80 \%$

False negative rate of screening test for all fetal aneuploidy is as below:

False Negative rate $=100 \%-$ sensitivity $=100 \%-80 \%$

$$
=20 \%
$$

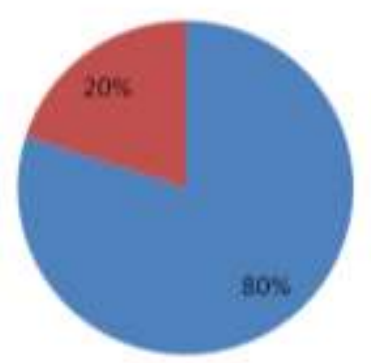

- Sensitivity

- False Negative rate

Figure 2: Pie chart showing sensitivity and false negative rate of screening test for all fetal aneuploidy.

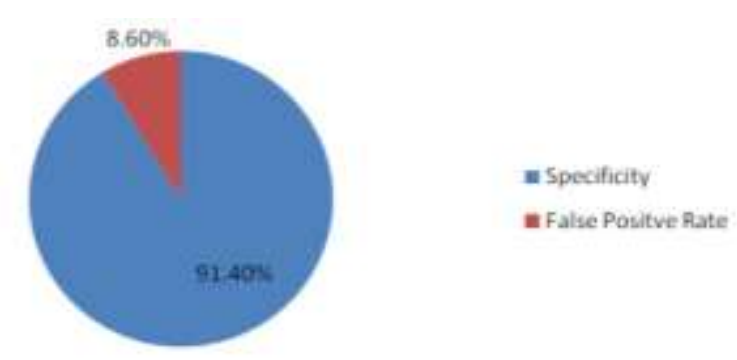

Figure 3: Pie chart showing specificity and false positive rate of screening test for all fetal aneuploidy.

Calculation of Specificity of screening test for fetal aneuploidies is as below:

Specificity $=\frac{\mathrm{TN}}{\mathrm{TN}+\mathrm{FP}} \times 100 \%=\frac{372}{372+35} \times 100 \%=91.4$

False Positive Rate of screening test for fetal aneuploidy can be calculated from the following equation:

False Positive rate $=100 \%-91.4 \%=8.6 \%$

Table 4: Screening test vis-à-vis normal fetus.

\begin{tabular}{|ll|}
\hline $\begin{array}{l}\text { Normal babies correctly detected as } \\
\text { normal by screening test (TN) }\end{array}$ & 372 \\
\hline $\begin{array}{l}\text { Normal babies wrongly detected as } \\
\text { abnormal by screening test (FP) }\end{array}$ & 35 \\
\hline Total number of normal babies & 407 \\
\hline
\end{tabular}

\section{DISCUSSION}

Down syndrome may be viewed as a tragedy, both by the family as well as by the society. The only way of preventing DS, at present, is prenatal diagnosis and termination of pregnancy. Diagnostic tests, till now, are invasive and attended with serious consequences like miscarriage beside the cost implications. Hence the diagnostic tests cannot be applied to the whole maternal population.

Screening tests detect those mothers who are at high risk to have Down syndrome baby and diagnostic tests are offered to them. In 1970s, main method of screening was advanced maternal age as the risk for many fetal aneuploidies increases with maternal age. Only 5\% of pregnant women were 35 years or more and only $30 \%$ of all Down Syndrome (DS) babies were born to this group. ${ }^{13}$ Thus the screening on the basis of maternal age, with a cut-off of 35 years or more does not identify the majority of DS babies. It has now been established that measurement of fetal NT thickness is an effective and early screening tool to identify fetal aneuploidies and particularly Trisomy 21 fetuses. ${ }^{11,13}$ This discovery of NT being a marker of chromosomal abnormalities led to the introduction of combination of age and NT as a screening method in the 1990s. ${ }^{7}$ 
The background risk of a woman carrying a chromosomally abnormal fetus is related to her age and gestational age. ${ }^{7}$ NT measurement provides a likelihood ratio which is multiplied with background risk to determine the adjusted risk. In general, higher the NT, higher the likelihood and thus higher the risk. ${ }^{7}$ Again, NT increases normally with gestation. Thus it is important to consider NT in relation to gestational age to appreciate if a given NT is high or not. ${ }^{14}$ This risk assessment calculation by taking all these factors, maternal age, gestational age and NT into consideration is contained in the Fetal Medicine Foundation (FMF) software that has been used in this study.

In this study, the sensitivity (also called 'detection rate') of this screening method, using a combination of maternal age and NT and taking a cut-off risk value of 1 in 300, for Trisomy 21 was $75 \%$ and for all types of aneuploidy was $80 \%$ for a false positive rate of $8.6 \%$. The results of our study are similar with the detection rate of $83.3 \%$ and $81.1 \%$ for Trisomy 21 and for all types of aneuploidy respectively in one large study on the population in USA with a false positive rate of $7.2 \%{ }^{15}$ Our study result is also consistent with the findings of the largest trial conducted ever on the sensitivity and false positive rate of this screening method. ${ }^{11}$

Various theories have been offered to explain the etiology for the nuchal fluid accumulation. ${ }^{16}$ Possible mechanisms for increased NT are: cardiac failure in association with the abnormalities of heart and great arteries, venous congestion in the head and neck due to various reasons, altered composition of the extracellular matrix, abnormal or delayed development of the lymphatic system and also failure of the lymphatic drainage, fetal anemia or hypoproteinemia, congenital infection of the fetus etc. ${ }^{17}$

Whatever the etiologies for fetal nuchal translucency are, measurement of nuchal translucency as a screening method has firmly taken place in practice. Our study has shown that NT measurement is effective in picking up the most of the cases. However, it needs to be clearly explained to the mothers while counselling that it is a screening method and can only indicate the risk. It can neither definitely diagnose nor definitely exclude fetal aneuploidy including Trisomy 21.

\section{CONCLUSIONS}

We conclude that NT measurement combined with maternal age is an effective prenatal screening method for fetal chromosomal abnormalities.

\section{ACKNOWLEDGEMENT}

We sincerely thank Dr. Shyamsundar Mandal, Statistical officer of Chittaranjan National Cancer Institute, for his help in statistical analysis of the data.
Funding: No funding sources Conflict of interest: None declared

Ethical approval: The study was approved by the Institutional Ethics Committee

\section{REFERENCES}

1. Luthardt FW, Keitges E. Chromosomal Syndromes and Genetic Disease. Encyclopedia of Life Sciences. 2001:5.

2. Geelhoed EA, Bebbington A, Bower C, Deshpande A, Leonard H. Direct health care costs of children and adolescents with Down syndrome. J Paediatr. 2011;159(4):1-12.

3. Binns V, Hsu N. Prenatal Diagnosis. Encyclopedia of Life Sciences. 2002:1-17.

4. Khalil A, Pandya P. Screening for Down syndrome. J Obstet Gynecol India. 2006;56:205-11.

5. Boulet SL, Molinari NA, Grosse SD, Honein MA, Correa-Villasenor A. Health care expenditures for infants and young children with Down syndrome in a privately insured population. J Paediatr. 2008;153:241-6.

6. Parker SE, Mai CT, Canfield MA, Rickard R, Wang Y, Meyer RE, et al. National Birth Defects Prevention Network. Updated national birth prevalence estimates for selected birth defects in the United States, 2004-2006. Birth Defects Res A Clin Mol Teratol. 2010;88:1008-16.

7. Nicolaides KH. First trimester diagnosis of chromosomal defects. In: The 11-13+6 weeks scan. Fetal Medicine Foundation: London; 2004:12,13,19.

8. Szabo J, Gellen J. Nuchal fluid accumulation in trisomy 21 detected by vaginosonography in first trimester. Lancet. 1990;3:1133.

9. Nicloaides KH, Azar G, Byrne D, Mansur C, Marks K. Fetal nuchal translucency: ultrasound screening for chromosomal defects in first trimester of pregnancy. Br Med J. 1992;304:867-9.

10. Saltvedt S, Almstrom H, Kublickas M, Valentin L, Bottinga R, Bui T-H, et al. Screening for Down syndrome based on maternal age or fetal nuchal translucency: a randomized controlled trial in 39572 pregnancies. Ultrasound Obstet Gynecol. 2005;25:537-45.

11. Snijders RJM, Noble P, Sebire N, Souka A, Nicolaides KH. UK multicentre project on assessment of risk of trisomy 21 by maternal age and fetal nuchal translucency thickness at 10-14 weeks of gestation. Lancet. 1998;351:343-6.

12. Pereira-Maxwell F. In: A-Z of Medical Statistics. A Companion for Critical Appraisal. Arnold. 1998:75, 77.

13. Lalkhen AG, McCluskey A. Clinical tests: sensitivity and specificity. Continuing Education in Anaesthesia, Critical care \& Pain. 2008;6:221-3.

14. Nicolaides KH. Screening for fetal aneuploidies at 11-13 weeks. Prenatal diagnosis. 2011;31:7-15.

15. Chasen ST, Sharma G, Kalish RB, Chervenak FA. First-trimester screening for aneuploidy with fetal 
nuchal translucency in a United States population. Ultrasound Obstet Gynecol. 2003;22:149 -51.

16. Acacio GL, Barini R, Junior WP, Ximenes RLS, Pettersen H, Faria M. Nuchal translucency: an ultrasound marker for fetal chromosomal abnormalities. Sau Paulo Med J Rev. 2001;119(1):19-23.

17. Nicolaides KH. Increased fetal nuchal translucency at 11-14 weeks. Prenatal diagnosis. 2002;22:308-15.
Cite this article as: Chaudhury K, Mukherjee K. Sensitivity and Specificity of a prenatal screening method using the combination of maternal age and fetal nuchal translucency thickness for fetal aneuploidy: a clinical study in Eastern India. Int $\mathbf{J}$ Reprod Contracept Obstet Gynecol 2016;5:148-53. 